\title{
Proposal and Verification of Area-limited Electroplating with Suction Tool
}

\author{
Atsushi Sato*, Wataru Natsu* \\ (Received January 14, 2015) \\ * Department of Mechanical Systems Engineering, Tokyo University of Agriculture and Technology, Tokyo \\ 184-8588, Japan \\ Abstract \\ Electroplating is used for corrosion protection, surface hardening, metal thin film manufacturing, etc. In \\ conventional electroplating, the workpiece is immersed in the plating solution, and the whole contact surface is \\ plated. Therefore, the mask operation and the removal of unnecessary plating film are needed for local plating in \\ the case of ornament plating and so on. However, these additional processes would lead to a substantial increase \\ in processing time and cost. In this research, a novel approach to realize local electroplating by using a suction \\ tool, with which the electrolyte is confined in the area between the tool electrode and workpiece, was proposed. \\ The results of the verification experiment showed that the maskless local electroplating can be performed, and \\ pattern plating such as characters is possible with the proposed method.
}

Keywords: Electroplating, suction tool, maskless, film forming, plating characteristics

\section{INTRODUCTION}

Electroplating is a process of coating a metallic material onto a workpiece surface by the electrochemical process, which is used for corrosion protection, surface hardening, metal thin film manufacturing, etc. In conventional electroplating, the workpiece is immersed in the plating solution, and the whole contact surface is plated. Therefore, masking related processes are needed for local plating, such as ornament plating and so on ${ }^{1)}$. However, these additional processes will cost much more time and expense. Moreover, the plating solution contains harmful substance and is usually restricted by law ${ }^{2}$. Using plating bath will increase the quantity of waste solution and cause environmental pollution.

Endo et al. ${ }^{3)}$ realized selective electrochemical machining by using an electrolyte suction tool. The electrolyte is retrieved by a suction pump through the central hole of the tool. The electrolyte exists only between the tool tip and workpiece surface. Meanwhile, Yamamura et al. ${ }^{4)}$ also realized local wet etching by using a concentric cylinder tool and two pumps, one for supplying the electrolyte to the gap area by pressure and one for recycling the supplied electrolyte from the gap area by suction. The basic principle for these two kinds of tools is therefore different in using just one suction pump or using one pressurizing pump with a suction pump. In this research, we proposed a method for maskless local electroplating by using a suction tool that was designed with the same principal as the electrolyte suction tool proposed by Endo et al. ${ }^{3)}$, and the effectiveness of the method was verified via experiments.

\section{OVERVIEW OF SUCTION TOOL AND EXPERIMENTAL SETUP}

\section{1 Principle of suction tool}

Principle of the suction tool is based on Bernoulli's theorem. Fig.1 shows the schematic of electrolyte circulation in the tool designed by Endo et

al. ${ }^{3)}$. In the case of broad gap-width, as shown in Fig.1(a), flow velocity of the inflow air from tool circumference is quite slow, and the pressure at the outlet of electrolyte storage area doesn't become very low. On the other hand, in the case of narrow gapwidth, as shown in Fig.1(b), flow velocity of the inflow air from tool circumference becomes much faster, and the pressure at the electrolyte outlet becomes much lower. The electrolyte is then sucked from the electrolyte storage area through the outlet and flows toward the suction hole by the pressure difference. Therefore, only when the gap-width is narrow, can the electrolyte flow into the gap between workpiece and the electrode surface, thus realizing the localization of electrochemical machining. However, this type of cylinder tool is difficult to be miniaturized, because the tool is made with two concentric cylinders. To solve this problem, a metal plate that sandwiched by acrylic resin parts was designed in this research to realized the miniaturization of tool electrode and reduce the area of plating.

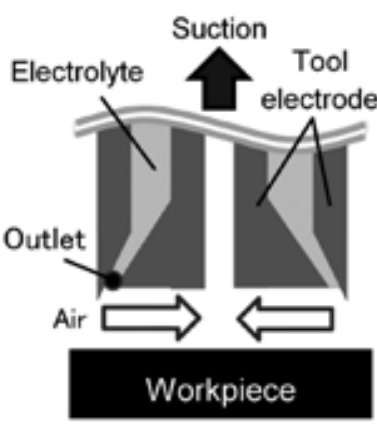

(a) For broad gap-width Fig. 1 Schematic of electrolyte circulation

\section{2 Experimental setup}

Overview of the experimental setup is shown in Fig.2(a), enlarged view of the tool tip is shown in Fig.2(b), and view from the tool bottom is shown in Fig.2(c). 


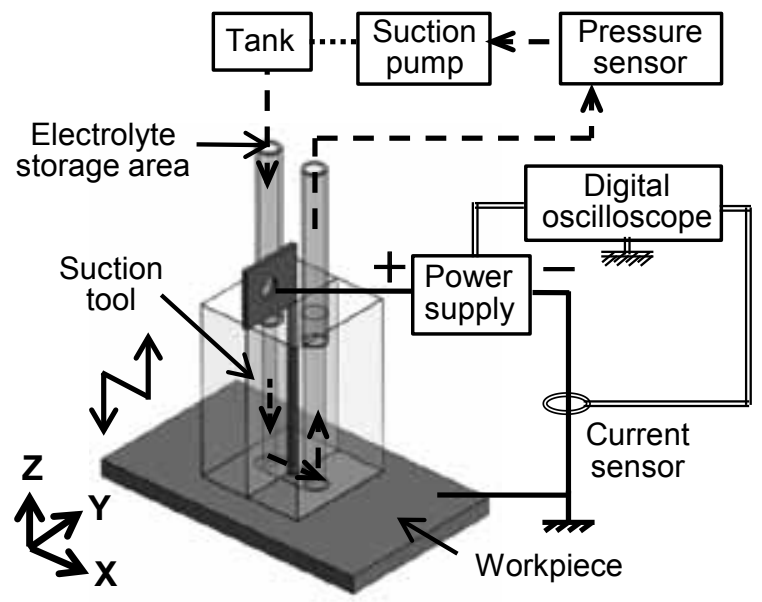

(a) Overview of experimental setup

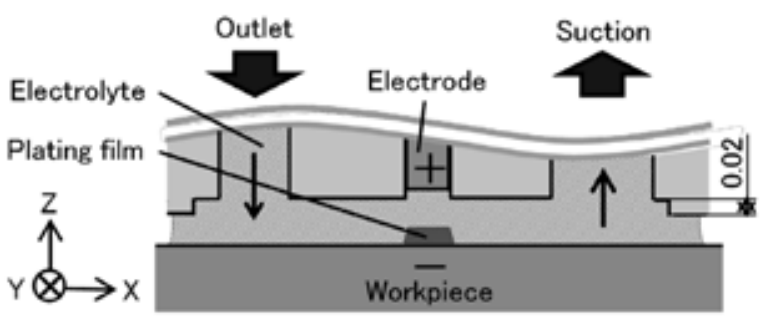

(b) Enlarged view of tool tip

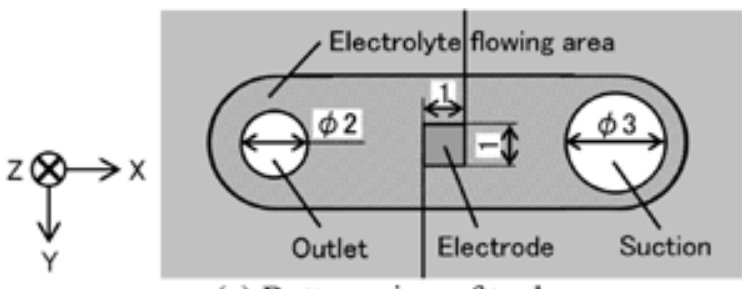

(c) Bottom view of tool

Fig.2 Experimental setup for local electroplating

As shown in Fig.2, the workpiece is fixed on a $\mathrm{X}$ $\mathrm{Y}-\mathrm{Z}$ stage, $\mathrm{Cu}\left(\mathrm{NO}_{3}\right)_{2} \mathrm{aq}$ is circulated in the suction tool as the plating solution, and the electroplating of material $\mathrm{Cu}$ is only performed on the selected area of workpiece surface. The suction tool is made of one metal plate and two acrylic resin parts that sandwiching the metal plate. The metal plate is processed with wire-EDM and its thickness is $1 \mathrm{~mm}$. As shown in Fig.2(b), the plating area is limited by connecting the tool electrode to a suction pump, which sucks the plating solution from the solution tank. The plating solution flows only on a part of the workpiece surface under the tool tip. The suction pump is an air pump (IWAKI, APN-60-W). The electrolyte is sucked from the outlet hole and flows through the electrolyte existing area then into the suction hole (see Fig.2(c)). The power device for machining is a bipolar power supply (TAKASAGO, BWS 120-2.5). The metal plate of electrode acts as anode and workpiece is cathode. The experiment was carried out with pulsed constant current. Brass (copper: about 60\%, zinc: about 40\%) was used as the electroplating workpiece to ensure adhesion of copper film. For pre-processing, the workpiece surface was polished mechanically by diamond slurry of particle diameter $0.25 \mu \mathrm{m}$. Table 1 shows the experimental conditions for electroplating.

Table 1 Experimental conditions for plating

\begin{tabular}{|c|c|}
\hline Plating solution & $22 \mathrm{wt} \% \mathrm{Cu}\left(\mathrm{NO}_{3}\right)_{2} \mathrm{aq}$ \\
\hline Workpiece material & Brass \\
\hline Tool material & Brass, Titanium \\
\hline Gap-width $[\mu \mathrm{m}]$ & 70 \\
\hline Power supply & Pulsed constant current \\
\hline Pulse period [ms] & 50 \\
\hline Pulse width $[\mathrm{ms}]$ & 5 \\
\hline
\end{tabular}

\section{3 Evaluation of film quality}

The quality factors of plating film include adhesion strength, film thickness and its uniformity, presence of defect and so on ${ }^{5}$. In this research, film quality is evaluated with the film thickness and defects. Film thickness and its uniformity are judged by the average thickness and the surface roughness of the film. The defect is judged by the appearance of the film. Shape of the plating film is measured 5 times each in $\mathrm{X}$ and $\mathrm{Y}$ direction at $0.1 \mathrm{~mm}$ interval. The average thickness is then calculated by averaging the thickness at all crossover points. The evaluation area of surface roughness is the $1 \mathrm{~mm}$ square area at the centre of the plating film.

\section{EFFECT OF ELECTRODE MATERIAL ON ELECTRODE WEAR CHARACTERISTICS}

In conventional copper electroplating, high purity electric copper is typically used as the soluble anode to supply metal ion into the plating solution ${ }^{6}$. On the other hand, the change in gap-width by anode wear and plating film may affect plating characteristics during local electroplating. Hence, the electrode wear characteristics is first examined by using brass (copper:60\%, zinc:40\%) as the easily soluble material and pure titanium as the hardly soluble material, because the passive film that prevents dissolution of metal is easily generated on the titanium surface ${ }^{7)}$. Although the wear of titanium electrode is expected to decrease, the anodic dissolution will still occurs, especially under pulse power supply. In contrast, brass has excellent machinability and the electrode can be easily fabricated using this material.

\section{1 Definition of electrode length wear ratio}

Electroplating without tool scanning movement is performed to compare electrode wear characteristics with the two electrode materials. Electrode length wear ratio $w_{l}$ is calculated by equation (1) and compared.

$$
w_{l}[\%]=\frac{l_{e}}{l_{f}} \times 100
$$


$l_{e}$ is electrode wear length, and $l_{f}$ is thickness of the plating film. $l_{e}$ is obtained by the difference of electrode length before and after experiment. The shape profile of bottom surface of tool electrode is measured 5 times each in $\mathrm{X}$ and $\mathrm{Y}$ direction at 0.1 $\mathrm{mm}$ interval with a contour measuring device, then the difference of average electrode length before and after experiment is calculated from these profile data. 3.2 Comparison of electrode wear characteristics

Thickness of the plating film and electrode wear length with both electrodes are shown in Fig.3, and electrode length wear ratio with both electrodes is shown in Fig.4. The applied current is $50 \mathrm{~mA}$ and processing time is $30 \mathrm{sec}$. The error bars show the maximum and minimum value of each item.

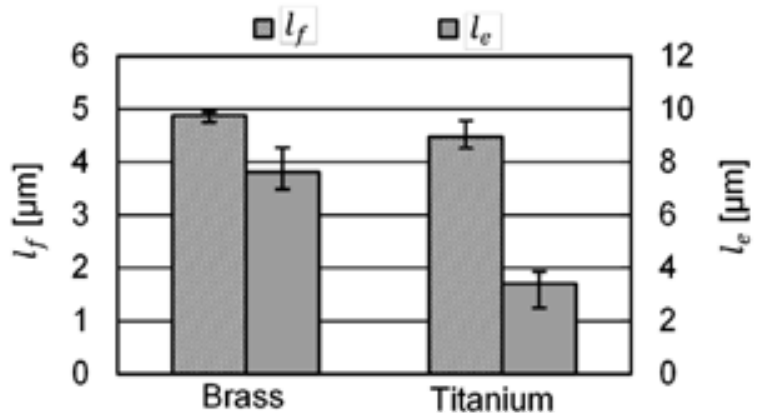

Fig.3 Effect of electrode material on $l_{f}$ and $l_{e}$

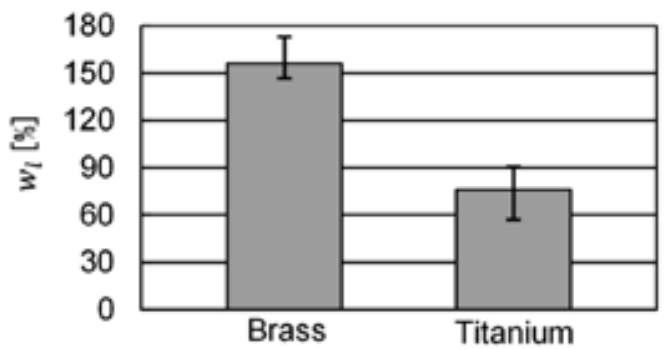

Fig.4 Effect of electrode material on $w_{l}$

As shown in Fig.3, the thicknesses are almost the same for both electrodes. However, the electrode wear length in the case of using brass electrode is about 2 times bigger than that of titanium electrode. Eventually, as shown in Fig.4, the electrode length wear ratio in the case of brass electrode is about 2 times higher than that of titanium electrode.

\section{FILM FORMING CHARACTERISTICS FOR DIFFERENT ELECTRODE MATERIAL}

Generally, thickness of the plating film is proportional to the processing time and applied current value per unit surface area ${ }^{8)}$. Accordingly, increasing current value is an effective way to improve film-forming rate. However, excessive current density tends to cause defects on the surface of plating film. In this chapter, the relation between current value and film thickness with both electrode materials is investigated, and the comparison of film forming characteristics is also discussed.

\subsection{Relation between current value and film thickness}

The relation between current value and film thickness is shown in Fig.5, and relation between current value and surface roughness $\mathrm{Ra}$ is shown in Fig.6. The processing time is $10 \mathrm{sec}$, and the error bars show the maximum and minimum value of each item.

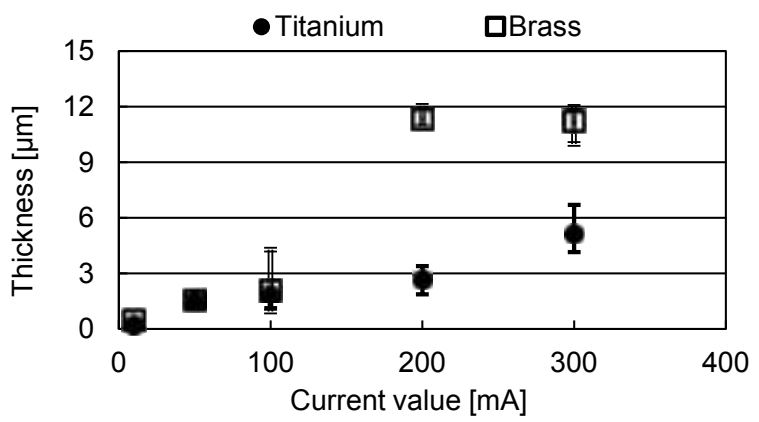

Fig.5 Relation between thickness and current value

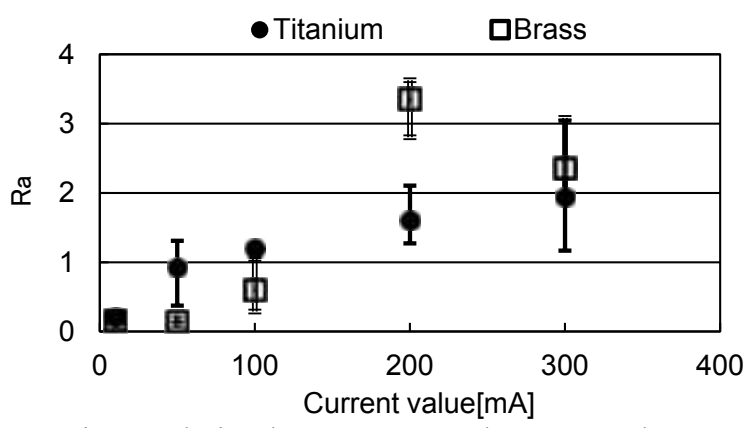

Fig.6 Relation between $\mathrm{Ra}$ and current value

As shown in Fig.5, the film for both electrodes becomes thicker with the increase of current value. Also, when the applied current is equal to or greater than $200 \mathrm{~mA}$, the film for brass electrode is about 2 to 4 times thicker than that of the titanium electrode. However, the film thickness remains almost the same, and its reproducibility is also better in the case of equal to or less than $50 \mathrm{~mA}$. In addition, by comparing Fig. 5 with Fig.6, it is found that in the case of less than $100 \mathrm{~mA}$, thicknesses of the plating films are almost the same for both electrodes, but the roughness of the surface of plating film when using the titanium electrode is coarser than that when using the brass electrode. Accordingly, it is thought that the brass electrode is excellent in uniformity of plating film than the titanium electrode.

\subsection{Effect of electrode material on uniformity}

Comparison of film shapes with different electrode materials at $50 \mathrm{~mA}, 100 \mathrm{~mA}$ and $200 \mathrm{~mA}$ along flow direction of the plating solution is shown in Fig.7.

By comparing Fig.7(a) with Fig.7(b), it is realized that the change in film thickness along flow direction of the plating solution is relatively small at $50 \mathrm{~mA}$. However, the change becomes bigger in the case of equal to or greater than $100 \mathrm{~mA}$. Also, to focus on the film shapes at $50 \mathrm{~mA}$ and $100 \mathrm{~mA}$, the increase 
tendency of thickness at both ends of the plating film is especially observed with the titanium electrode. This tendency was similar to that along the direction perpendicular to the solution flow direction. It is considered that this tendency is caused by the effect of passive film generated on the titanium surface. Concentration of current at the electrode corner is thought to be caused by the passive film that increases the resistance between the electrodes. The voltage value was measured during electroplating to observe the difference. Although it varied depending on the current value, the voltage value was about 1 to $2 \mathrm{~V}$ in the case of brass electrode and about 20 to $40 \mathrm{~V}$ in the case of titanium electrode. That is, the voltage value on titanium electrode is much higher than that on brass electrode. By the way, the decomposition voltage of metal salt solution is about 1 to $2 \mathrm{~V}$, and conventional electroplating is performed near the decomposition voltage ${ }^{8)}$. Therefore, the voltage value with brass electrode is closer to the ideal voltage value of conventional electroplating.

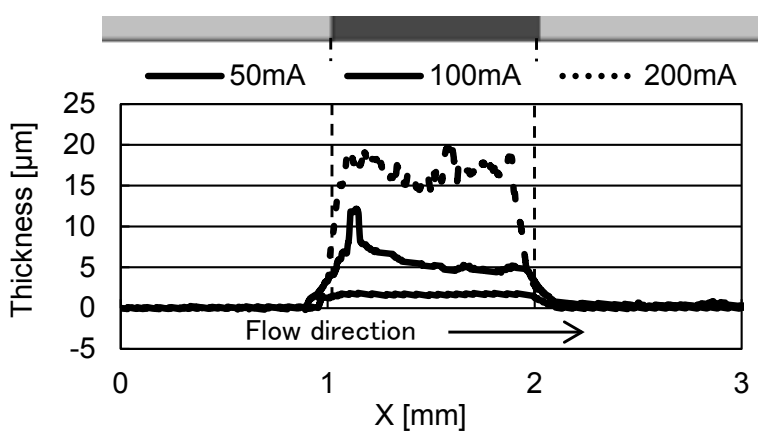

(a) Film shape by using a brass electrode

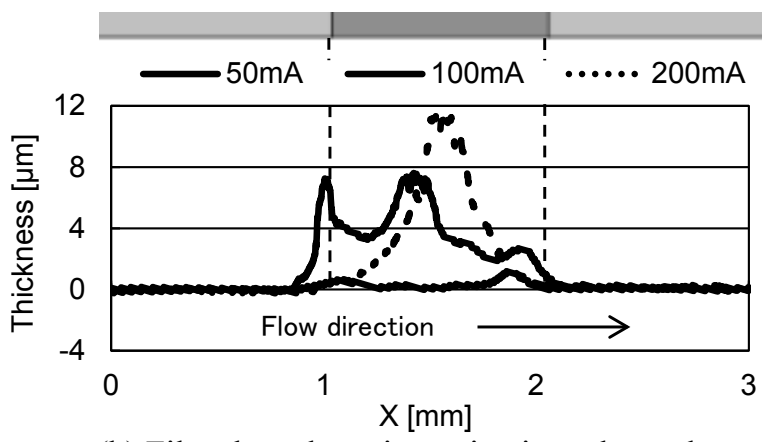

(b) Film shape by using a titanium electrode

Fig.7 Comparison between film shapes with different electrode materials

\subsection{Comparison of plating film appearance}

In this section, the plating film appearances with both electrodes are compared at $50 \mathrm{~mA}$, at which the smallest deviation of film thickness and better surface roughness for both electrodes were observed. Comparison result of plating film appearance is shown in Fig.8.

As shown in Fig.8(a), the surface obtained with brass electrode has much less defect such as pit and burnt deposit, and better plating surface was achieved. However, in Fig.8(b), the surface of plating film obtained with titanium electrode has non-plated part and defect of burnt deposit in the processed area. For this reason, it can be concluded that the appearance of plating film by brass electrode is better than that by titanium electrode.

Fig.9 shows the appearances of plating film by brass electrode at $100 \mathrm{~mA}$ and $200 \mathrm{~mA}$.

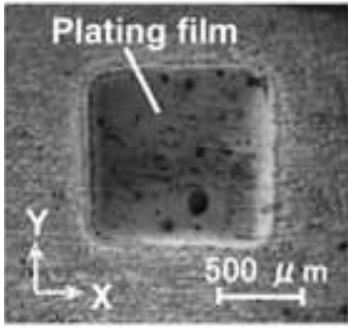

(a) Brass electrode

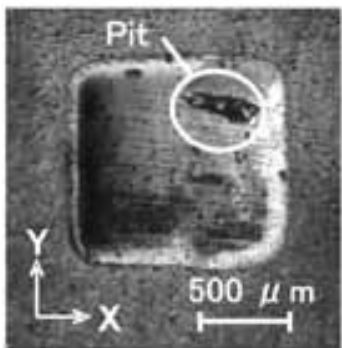

(a) $100 \mathrm{~mA}$

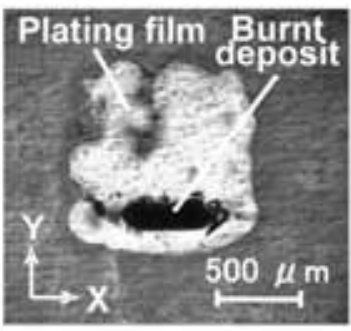

(b) Titanium electrode

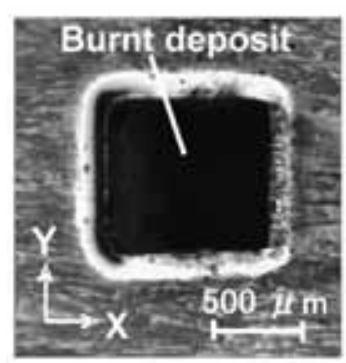

(b) $200 \mathrm{~mA}$
Fig.9 Film appearance under $100 \mathrm{~mA}$ and $200 \mathrm{~mA}$ by using a brass electrode

The pit appeared at $100 \mathrm{~mA}$ and the burnt deposit appeared at $200 \mathrm{~mA}$ with brass electrode. It is thought that these defects are mainly caused by the excessive cathode current density ${ }^{9}$. If we calculate the area where current flows as the product of plating film widths in $\mathrm{X}$ and $\mathrm{Y}$ direction, then the area is about $1.32 \mathrm{~mm}^{2}$ at $50 \mathrm{~mA}$ and the cathode current density is about $38 \mathrm{~mA} / \mathrm{mm}^{2}$. This cathode current density value is about 100 to 130 times higher than the standard value in copper sulfate plating bath with the same kind of electrolyte ${ }^{10)}$.

\section{FILM FORMING CHARACTERISTICS IN SCANNING PROCESSING}

It is thought that complicated pattern film can be formed by scanning the suction tool electrode. In this chapter, the film forming characteristics in scanning processing with both electrodes is reported. All the experiments in this chapter are conducted with onetime tool scan, which means that there is no overlap of plating films.

\subsection{Evaluation of scanning processed surface}

The tool was scanned $3 \mathrm{~mm}$ in $+\mathrm{X}$ direction. The area of evaluation is shown in Fig.10. The dot line part was measured by a contour measuring device. 


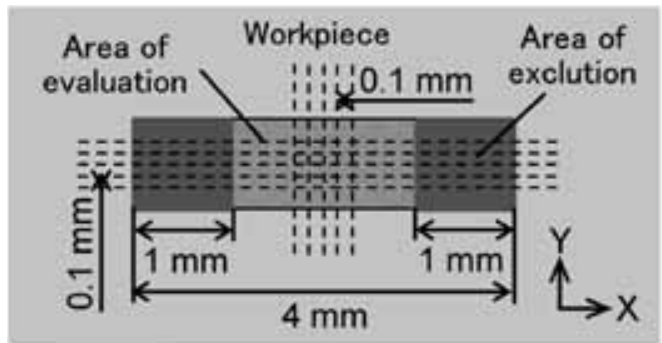

Fig.10 Method of film evaluation

5.2 Relation between scan rate and film thickness

In the case that pattern film such as characters is rapidly formed, it is necessary to speed up the tool electrode at a suitable current value. Therefore, the relation between film thickness and scan rate was investigated with both electrode materials. The relation between thickness and scan rate is shown in Fig.11, and the relation between surface roughness and scan rate is shown in Fig.12. The current value was $50 \mathrm{~mA}$ which was good for the reproducibility of thickness and the appearance of plating film with the brass electrode.

As shown in Fig.11, the film thicknesses with both electrodes are almost the same, and the change tendency of film thickness with scan rate is also the same. Also, the thickness is inversely proportional to scan rate. Moreover, the surface roughness with the brass electrode is always better than that with the titanium electrode. In addition, the surface roughness with titanium electrode becomes coarser with the decrease of scan rate. In contrast, better surface roughness can be achieved with brass electrode regardless of scan rate.

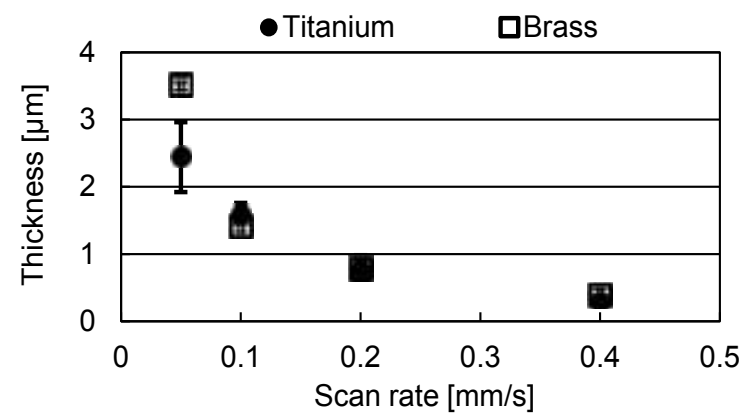

Fig.11 Relation between thickness and scan rate

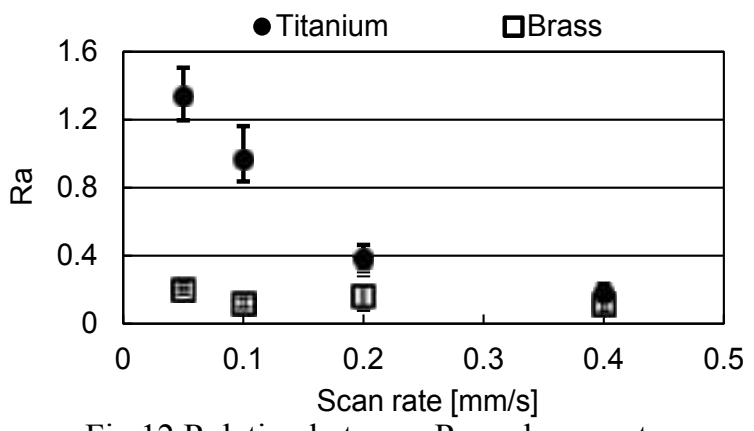

Fig.12 Relation between $\mathrm{Ra}$ and scan rate

\subsection{Effect of scanning on uniformity of film} thickness

The uniformities of film thickness at $0.4 \mathrm{~mm} / \mathrm{s}$ and $0.05 \mathrm{~mm} / \mathrm{s}$ were compared. The film shape along the scanning direction is shown in Fig.13(a). The film shape along the direction perpendicular to the scanning direction is shown in Fig.13(b).

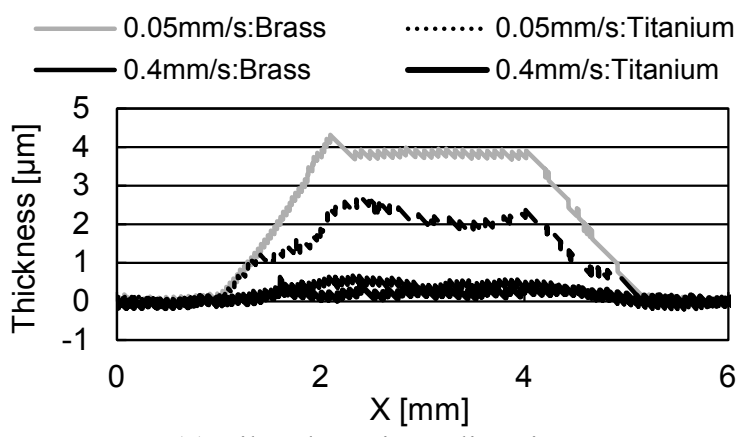

(a) Film shape in $X$ direction

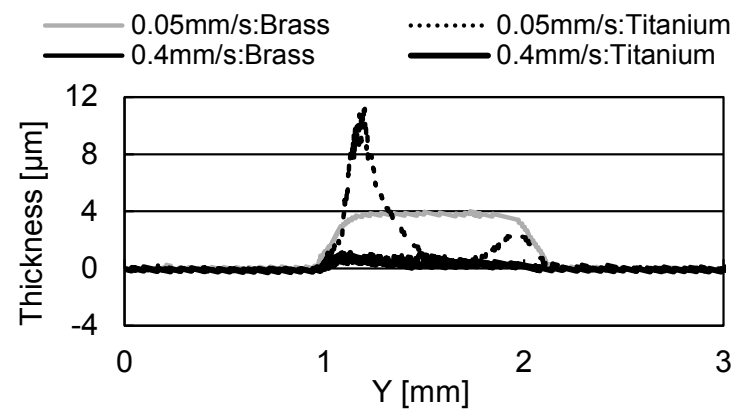

(b) Film shape in Y direction

Fig.13 Film shape under different tool material and rate

As shown in Fig.13(a), along the scanning direction, the uniformity of film thickness is not so different between both electrodes regardless of scan rate in the evaluation area. However, it is found from Fig.13(b) that in the direction perpendicular to the scanning direction, electrode materials have large effect on the uniformity at $0.05 \mathrm{~mm} / \mathrm{s}$. At $0.05 \mathrm{~mm} / \mathrm{s}$, plating film with brass electrode is uniformly formed. Meanwhile, increase tendency of thickness at both ends of the plating film is observed with the titanium electrode. It is thought that the deterioration of uniformity is caused by comparatively slow scan rate.

In Fig.13(b), it is observed that the profile in the Ydirection is skewed to the left for the $0.05 \mathrm{~mm} / \mathrm{s}$ Titanium sample. Such skewed profiles are sometimes observed in experiments, but the skewed directions are not always the same. Therefore, it is thought that the skewed profile is caused by accidental uneven electrolyte flow.

\subsection{Effect of scan rate on plating film appearance}

The burnt deposit is observed on the plating film with titanium electrode at $0.05 \mathrm{~mm} / \mathrm{s}$, as shown in Fig.14. However, defects such as pit and burnt deposit were not observed in the case of comparatively fast scan rate. On the other hand, the plating film with 
brass electrode did not show defects caused by excessive current density regardless of scan rate. Therefore, it is thought that slow scan rate is the cause of defect in the case of titanium electrode.

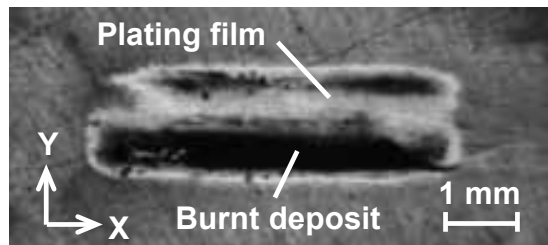

Fig. 14 Appearance at $0.05 \mathrm{~mm} / \mathrm{s}$ with titanium electrode

\subsection{Formation of pattern film}

The preceding sections confirmed that area-limited electroplating can be realized with a suction tool. However, it is necessary to verify whether the electroplating method proposed in this research is actually applicable to the formation of pattern film. Therefore, a brass electrode that was good for the quality of plating film was selected, and the formation of pattern film has been tried. The scan rate was 0.4 $\mathrm{mm} / \mathrm{s}$ and the current value was $50 \mathrm{~mA}$. The appearance of formed pattern film is shown in Fig.15, and the film thickness is about $0.4 \mu \mathrm{m}$. As shown in the picture, the letters "ECM" can be clearly recognized, despite some corrosion by the plating solution. Therefore, it can be said that the complicated pattern film such as characters can be formed by scanning a suction tool.

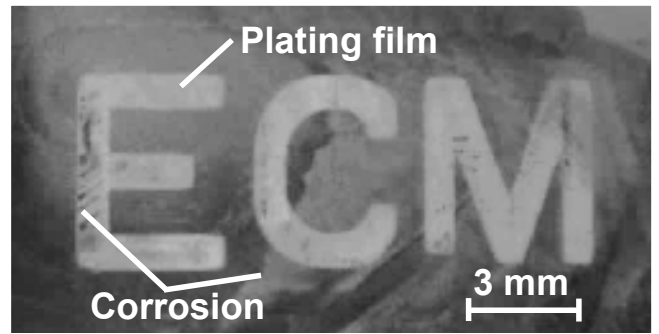

Fig.15 Pattern shaped by tool scanning

\section{EFFECT OF SCANNING TIMES ON FILM- FORMING CHARACTERISTICS}

Recently, 3D printers began to attract attention since the equipment enables quick and inexpensive manufacture of trial products for new product development ${ }^{11),}{ }^{12}$. Meanwhile, Kunieda et al. ${ }^{13}$ realized local adhesion processing and laminating fabrication by electrolyte jet machining with the polarity opposite to removal processing. The laminating fabrication can also be similarly realized by area-limited electroplating that proposed in this research. However, the film forming characteristics in a lamination process may be different from those in the one-time plating process

\subsection{Effect of scanning times}

The processing time was $1 \mathrm{~min}$, and the experiment was implemented by changing the number of scanning times. The relation between film forming characteristics and the scanning times is shown in Fig.16. The electrode material is brass, and the current value is $50 \mathrm{~mA}$. The one time scanning is performed along direction $+\mathrm{X}$ once, and the two times scanning is 1 round-trip, that means one time in $+\mathrm{X}$ direction and one time in -X direction. In addition, the three times scanning is 1.5 round trips. It is found from Fig. 16 that the thickness and surface roughness were not affected by the lamination of plating films, under the conditions in this research.

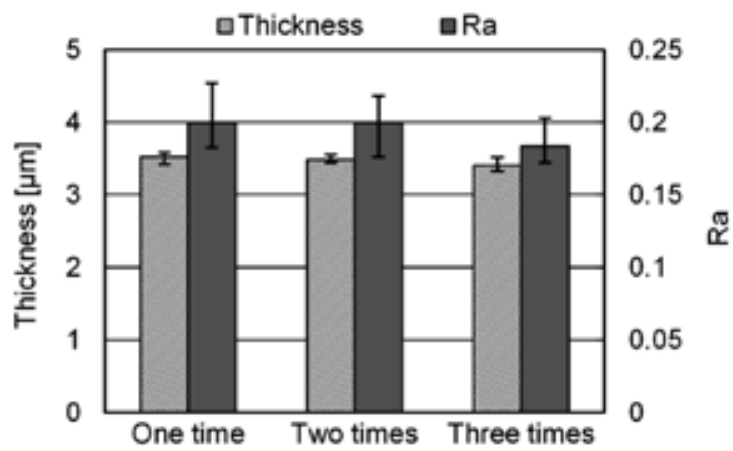

Fig.16 Relation between scanning times and film thickness

\subsection{Effect of lamination on plating film appearance}

The plating film appearance in one time scanning was compared with the appearance in three times scanning to investigate the effect of lamination on plating film appearance. The result is shown in Fig.17. Some black spots are observed on the plating film surfaces. In the electrolytic copper plating under excessive cathode current density, the plating film with dark red appearance and rough surface caused by pits is usually observed ${ }^{9)}$. However, as shown in Fig.16, there is no obvious difference in the surface roughness between the results of Fig.17(a) and Fig.17(b), although more black spots are observed in Fig.17(a). Therefore, it is thought that the black spots are caused by corrosion of the plating solution, not by excessive current density.

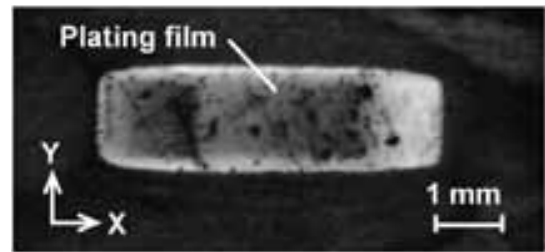

(a) Appearance of one time scanning

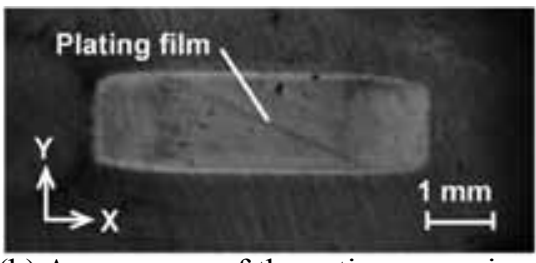

(b) Appearance of three-time scanning

Fig.17 Effect of lamination on film appearance 
As shown in Fig.17, the plating film surface did not have defects despite lamination. Therefore, it is clear that the number of scanning times does not affect film forming characteristics in this experiment.

\section{CONCLUSIONS}

In this research, area-limited electroplating with suction tool was proposed and the effectiveness was verified via experiments. In addition, influences caused by tool electrode material and processing conditions were investigated. The results are summarized as follows:

1) Local electroplating can be achieved by using the proposed suction tool, and the forming of pattern film such as characters is possible.

2) Electrode length wear ratio of titanium electrode is about half of that of brass electrode.

3 ) On the quality of plating film, the brass electrode is better than that of the titanium electrode.

4) The influence of lamination on film thickness is small, when the total processing time remains the same.

\section{ACKNOWLEDGMENTS}

This research was partially supported by the JSPS(Grants-in-aidfor Scientific Research 25630021). The authors also would like to exress their thanks to Dr. Dahai Mi for his help in preparing this manuscript.

\section{REFERENCES}

1) I. Okada et al.: Minute Wiring Formation Technique using Metal Nano Ink, SEI Technical Review, item(168), pp.90-92, (2006). (In Japanese)
2) T. Yamana: Introduction to Plating Work (Augmented Edition), Rikogakusha Publishing, pp.204-205, (2003). (In Japanese)

3) K. Endo et al.: Proposal and Verification of Electrolyte Suction Tool with Function of Gapwidth Detection, International Journal of Electrical Machining No.19, pp.34-39, (2014).

4) K. Yamamura: Fabrication of Ultra Precision Optics by Numerically Controlled Local Wet Etching, Annals of the CIRP 56, pp. 541-544, (2007)

5) Y. Okamura: The Basic and Know-how of The Plating which is Helpful in The Design Spot, Nikkan Kogyo Shimbun, p37, (2009). (In Japanese)

6) T. Hujino et al.: Plating Practical Use Manual, Kougaku Tosho, pp.14-15, (1978). (In Japanese)

7) C.W.Skaggs:ibid., June 15, p94, (1964)

8) K. Maruyama: Plating Business Handbook, Nikkan Kogyo Shimbun, pp.9-14, (1983). (In Japanese)

9) Japanese Plating Technology Meeting for The Study: Practical Use Plating for Spot Engineers ( I ), Maki Bookstore, pp.89-97, (1978). (In Japanese)

10) K. Maruyama: Beginner's Class Plating, Nikkan Kogyo Shimbun, pp.46-47, (1995). (In Japanese)

11) T. Nakagawa et al.: Laminated Molding System, Kogyo Chosakai Publishing Co., pp.1-3, (1996). (In Japanese)

12) M. Mizuno et al.: 3D Printer for The First Time, Gijutsu-Hyohron, p16, (2013). (In Japanese)

13) M.Kunieda et al.: Rapid Prototyping by Selective Electro Deposition Using Electrolyte Jet, CIRP Annals, 47, (1), 161-164, (1998). 